\title{
Patients' satisfaction and associated factors among private wing patients at Bahirdar Felege Hiwot Referral Hospital, North West Ethiopia
}

\author{
Yeshambel Agumas Ambelie*, Amsalu Feleke Demssie, Measho Gbreslassie Gebregziabher \\ Department of Health Service Management and Health Economics, Institute of Public Health, College of Medicine and Health Sciences, \\ University of Gondar, Ethiopia
}

\section{Email address:}

tgyesh@gmail.com (Y. A. Ambelie), felekeam@yahoo.com (A. F. Demssie), measho2013@gmail.com(M. G. Gebregziabher)

\section{To cite this article:}

Yeshambel Agumas Ambelie, Amsalu Feleke Demssie, Measho Gbreslassie Gebregziabher. Patients' Satisfaction and Associated Factors among Private Wing Patients at Bahirdar Felege Hiwot Referral Hospital, North West Ethiopia. Science Journal of Public Health. Vol. 2, No. 5, 2014, pp. 417-423. doi: 10.11648/j.sjph.20140205.17

\begin{abstract}
Background: Patient satisfaction has become well established as an important consideration in health care provision and an integral component of measuring quality health service. However, health care outcomes still have been defined by professionals and have largely reflected a clinical perspective, particularly in low income countries including Ethiopia. This study aimed to assess patients' satisfaction and associated factors among adult private wing patients at Bahirdar Felege Hiwot Referral Hospital, Amhara National Regional State, North West Ethiopia. Methods: Institutional based quantitative cross sectional study was conducted from March 12 to April 30, 2014 on 384 service users using systematic random sampling technique. Data were collected by using "structured interviewer administered questionnaire', entered using EPI INFO version 3.5.3, and analyzed by SPSS for windows version 20.0. Variables having $\mathrm{p}<0.2$ at bi variable analysis were fitted to multi variable analysis, OR, P-value and 95\% CI were computed to show the association of variables. Result: From the total sample size $(n=422)$, three hundred eighty four patients were interviewed, of which $70.3 \%$ were outpatients. The results of the study showed that overall patient satisfaction with the health services rendered at the private wing of the hospital was $57.8 \%$ at $95 \%$ CI (52.8\%-63.1\%) computed from satisfaction measuring items. Among measuring items, satisfaction was reported to be highest $(93.2 \%)$ to the cleanliness of the rooms, and least for availability of signs and directions to ease the way in the private wing $(25 \%)$ to the scale satisfied. Being outpatient reduces satisfaction by 59\% as compared with inpatients (AOR: 0.411(0.243-0.696). Conclusion and recommendation: Overall private wing patient satisfaction (57.8\%) at 95\% CI (52.8\%-63.1\%) is lower as compared with recent studies in public hospitals of Ethiopia. Age, occupation and patient department are significantly associated with patient satisfaction. The hospital need to strengthen efforts to deliver integrated quality services to improve patient satisfaction at the private wing.
\end{abstract}

Keywords: Private Wing, Hospital, Outpatients, Inpatients, Satisfaction

\section{Introduction}

Measuring patients' satisfaction has become an integral part of hospital management strategies for quality assurance and accreditation process in most countries, distinguishing that lack of sufficient data can severely inhibit an organization's ability to understand its strengths and to target areas in which performance can be improved $(1,2)$

Measuring patient satisfaction is a way of assessing the process of care, describing the patient's viewpoint, and evaluating care by reflecting patient views back into the system and through comparing facilities (3). It is also the best source of information about a health care systems' communication, education and pain management process that has enhanced patient-centered high quality care $(4,5)$. Studies indicated that a satisfied patient has complied with the medical treatment prescribed, provider recommendation delivered, and continually using medical services at a specific health provider, which might resulted with, enhanced disease healing process, healthier and happier clients, whom contributing to the development of the country (6-9).

Studies conducted in different public hospitals in Ethiopia 
come up with overall client satisfaction ranging from $22.0 \%$ in Gondar to $77 \%$ in Jimma $(1,6,10-14)$. Different Studies reported that: patient provider relationship (courtesy, listening, consultations, etc), medical care and information, physical environment, lack of adequate transportation, in-patient services, hospital facilities and access to care, waiting time and cost of treatment, visiting of Doctors after registration, inadequate physical examination by providers, laboratory procedures, re-visiting of the doctor for evaluation with laboratory results, prescription paper for drugs and supplies, availability of prescribed drugs/ medications from the hospitals' pharmacies, difficulty to locate different sections, cleanliness of toilets/bathrooms, availability of drinking water etc. were the frequently faced problems affecting satisfaction(1, 2, 5, 6, 9-16).

Health care outcomes still have been defined by professionals and have largely reflected a clinical perspective, particularly in low income countries like Ethiopia, which is well differ from that of clients' outlook, considered as a difficult concept to be measured and interpreted; also considerably ignored by health care managers, which contradicted with suggestions of the emerging health care literatures towards patient views for the success of facilities $(2,3,17)$. No studies has been published on private wing patients' satisfaction and associated factors under public hospitals (18), as well as, it is new initiative with rapid progress of scaling up country wide in Ethiopia, i.e. four hospitals in 2010, eighteen hospitals in 211, thirty one hospitals in 212 has launched it, and more hospitals, work to inaugurate it $(19,20)$.

Therefore, this study assessed private wing patient satisfaction and associated factors at Bahirdar Felege Hiwot Referral Hospital, to support providers of care by modifying their provision of services to make their patients more satisfied.

\section{Methods}

The study was conducted from March 12 to April 30, 2014 to assess private wing patients' satisfaction and identify associated factors at Bahirdar Felege Hiwot Referral Hospital, Bahirdar Town, Amhara National Regional State, 563 kilometers from Addis Ababa (capital city of Ethiopia), North West, that deliver inpatient and outpatient Medical services for the community whom has had afford full cost recovery for the services since April 2011.

Institutional based cross-sectional study design was conducted. The study includes both adult ( $>=18$ years) inpatients and outpatients enrolled at the private wing of Bahirdar Felege Hiwot Referral Hospital excluding seriously ill patients in the study period.

The sample size was determined by single population proportion formula with the following assumptions; proportion of the population had taken as $50 \%$ to get maximum sample size, since the private wing patients satisfaction at public hospitals was not known, at 95\% confidence level and margin of error 5\%, considering $10 \%$ non-response rate the sample size was 422.

The sample was obtained by allocating patients proportionally to private wing adult inpatients and outpatients and the study samples were taken from each department under study by systematic random sampling.

The dependent variable were private wing patient satisfaction, likewise the independent variables included were Socio demographic factors (Age, Sex, Marital status, Educational level, Occupation, Residence, Frequency of visit, Patient department); Enabling Factors (Cost of treatment, Income, Pre information, Convenience)

Healthcare facility factors: Communication\& relationships (Courtesy \& respect, Privacy, Information), Diagnosis \& Medication- (Waiting time, BP/Thermometer/Waiting scale, Drugs), Physical environment- (Sign \& direction indicators, Toilets/ bathroom, Drinking water), Convenience- (Services, Cost, time)

The operational definitions of some words or phrases are stated as follows:

Private wing: An annex, or an extension within a hospital where medical services are provided to patients at full-cost recovery (that is, no subsidies).

Patient Satisfaction: Perception of the outcome of care and the extent it meets patients need and expectation

Inpatients: Patients who had a hospital stay $>1$ day

Outpatients: Received care at the health facility on a day the survey was conducted

Patient department: Service area serving either outpatients, or inpatients

Waiting time: The interval between departures from registration for outpatient service $\&$ seen by a doctor i.e.at waiting station of the private wing.

Satisfied: In this study refers participants who have the overall satisfaction of median score equal and above 44 on the given items to measure satisfaction.

Recent Studies: In this survey refers studies done in public hospitals of Ethiopia since 2010.

Consumer Assessment of Healthcare Providers and Systems (CAHPS) questionnaire was chosen as a tool to assess patient satisfaction in low-income countries(2).

It was modified for use and translated into Amharic (the predominant local language in Amhara National Regional State) by two Ethiopian language teachers (1 Amharic \&1 English) and back-translated to check the consistency of the translation and then pre-tested with 20 (5\% of sample size) patients with the same set up, but out of study area to identify questions that were unclear or confusing. Based on the pre-test data, the survey items were slightly modified and final questionnaire were developed for fielding.

The CAHPS tool is a multiple item scale to measure patient satisfaction covered four domains of care: Communications and relationship, Diagnosis and medications, Physical environment, and Convenience. Items were scored using a 4-point Likert scale, ranging from ( $1=$ very dissatisfied) to $(4=$ very satisfied $)(2)$.

Waiting time after registration to see the doctor was asked only to outpatients, and length of admission days were asked 
only to inpatients. The survey also includes whether they would recommend this private wing to friends and family (Yes / No), and there was a question asking to rate personal satisfaction to services in the private wing (Satisfied / Dissatisfied).

Data were collected by pre-tested 'interviewer administered questionnaire', entered using EPI INFO version 3.5.3, exported and analyzed using SPSS for windows version 20 , by checking missing values, computing calculable variables \& recoding.

Summary statistics of socio demographic variables were presented using frequency tables and graphs. Bi variable analysis was done and variables with p-value less than 0.2 were included in the multiple logistic regression analysis. Odds ratio and $95 \%$ confidence intervals were also computed along with the corresponding $\mathrm{p}$-value.

The study was reviewed and approved by Institutional Research Review Board of Institute of Public Health, University of Gondar, and Approval was got from Bahirdar Felege Hiwot Referral Hospital Chief executive. The purpose and the importance of the study were explained, verbal and written consent was obtained from each participant.

\section{Results}

\subsection{Socio Demographic Characteristics of Participant}

Among the total sample size $(n=422)$ three hundred eighty four adult patients' were interviewed, giving a response rate of $91 \%$, of which $270(70.3 \%$ ) were outpatients.

There was comparable gender distribution with slight male predominance $196(51 \%)$ and $123(32 \%)$ of the respondents were between the age group of 28-37 years. The mean age of respondents was 36.12 \pm (SD) (10.973) years.

Pertaining to occupation of respondents 121 (31.5\%) were merchants. Furthermore, $(90.6 \%)$ of respondents were new visitors, and $62.8 \%$ had no pre-information about the private wing (Table 1).

\subsection{Respondents Score on Satisfaction Measuring Items}

Among the total respondents $(\mathrm{n}=384), 93.2 \%$ were responded as "satisfied" to cleanliness of service delivery rooms, whereas $70.8 \%$ as "dissatisfied" to availability of sign and direction indicators to ease the way in the hospital (Table 2).

\subsection{Determining Patient Satisfaction}

Overall satisfaction was $57.8 \%$ at $95 \%$ CI (52.8\%-63.1\%) computed from satisfaction measuring items (Figure 1).

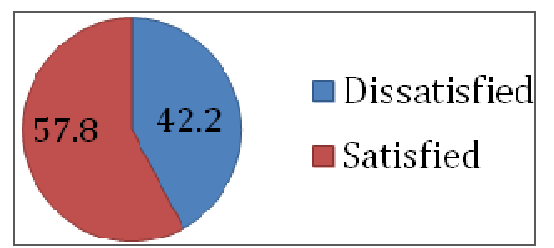

Fig. 1. Diagrammatic presentation of private wing patient satisfaction in BFHRH, 2014

Table 1. Baseline characteristics of respondents at BFHRH, 2014(n=384)

\begin{tabular}{|c|c|c|}
\hline Items & Number & Percent \\
\hline \multicolumn{3}{|l|}{ Patient Department } \\
\hline Inpatient & 114 & 29.7 \\
\hline Outpatient & 270 & 70.3 \\
\hline \multicolumn{3}{|l|}{ Sex } \\
\hline Male & 196 & 51.0 \\
\hline Female & 188 & 49.0 \\
\hline \multicolumn{3}{|l|}{ Age } \\
\hline $18-27$ & 109 & 28.4 \\
\hline $28-37$ & 123 & 32.0 \\
\hline $38-47$ & 82 & 21.4 \\
\hline $48+$ & 70 & 18.2 \\
\hline \multicolumn{3}{|l|}{ Occupation } \\
\hline Farmer & 98 & 25.5 \\
\hline Merchant & 121 & 31.5 \\
\hline Government employee & 59 & 15.4 \\
\hline Private employee & 31 & 8.1 \\
\hline Others $^{@}$ & 75 & 19.5 \\
\hline \multicolumn{3}{|l|}{ Family income } \\
\hline$<1200$ & 98 & 25.5 \\
\hline $1200-2250$ & 98 & 25.5 \\
\hline $2251-2968.50$ & 92 & 24.0 \\
\hline$>2968.50$ & 96 & 25.0 \\
\hline \multicolumn{3}{|l|}{ Marital Status } \\
\hline Not married & 104 & 27.1 \\
\hline Married & 247 & 64.3 \\
\hline Divorced & 22 & 5.7 \\
\hline Widowed & 11 & 2.9 \\
\hline \multicolumn{3}{|l|}{ Residence } \\
\hline Rural & 152 & 39.6 \\
\hline Urban & 232 & 60.4 \\
\hline \multicolumn{3}{|l|}{ Educational Level } \\
\hline Unable to read and write & 53 & 13.8 \\
\hline Can read and write & 63 & 16.4 \\
\hline Grade 1-6 & 63 & 16.4 \\
\hline Grade $7-12$ & 71 & 18.5 \\
\hline Certificate and above & 134 & 34.9 \\
\hline \multicolumn{3}{|l|}{ Frequency of visit } \\
\hline New & 348 & 90.6 \\
\hline Repeat & 36 & 9.4 \\
\hline \multicolumn{3}{|l|}{ Pre-information } \\
\hline No & 241 & 62.8 \\
\hline Yes & 143 & 37.2 \\
\hline
\end{tabular}

@ = Student, House wife, No occupation 
Table 2. Satisfaction of patients with the different components of health care services, Private wing BFHRH, 2014 ( $n=384$ )

\begin{tabular}{|c|c|c|c|c|}
\hline Items & Very dissatisfied $n(\%)$ & Dissatisfied n(\%) & Satisfied & Very Satisfied n(\%) \\
\hline \multicolumn{5}{|l|}{ Communication and relationship items } \\
\hline 1. Courtesy and respect & $0(0)$ & $49(12.8)$ & $324(84.4 \%)$ & $11(2.9)$ \\
\hline Doctors listen carefully & $0(0)$ & $70(18.2)$ & $306(79.7)$ & $8(2.1)$ \\
\hline Doctors nurses explain things in understandable way & $0(0)$ & $95(24.7)$ & $280(72.9)$ & $9(2.3)$ \\
\hline Get enough privacy & $0(0)$ & $100(26.0)$ & $279(72.7)$ & $5(1.3)$ \\
\hline Get enough time to discuss problems & $0(0)$ & $158(41.1)$ & $225(58.6)$ & $1(0.3 \%)$ \\
\hline 6. Information regarding to symptoms lookout & $0(0)$ & $215(56.0)$ & $169(44.0)$ & $0(0)$ \\
\hline \multicolumn{5}{|l|}{ Diagnosis and Medication items } \\
\hline $\begin{array}{l}\text { 7. Satisfied with waiting time to be seen by a Doctor } \\
\text { after registration }\end{array}$ & $0(0)$ & $56(14.6)$ & $326(84.9)$ & $2(0.5 \%)$ \\
\hline $\begin{array}{l}\text { 8. Doctor/ nurse use BP/thermometer/ waiting for } \\
\text { diagnosis }\end{array}$ & $0(0)$ & $43(11.2)$ & $340(88.5)$ & $1(0.3)$ \\
\hline 9. Laboratory result were described & $3(0.8)$ & $101(26.3)$ & $279(72.7)$ & $1(0.3)$ \\
\hline Doctor/ nurse told what the medication was for & $2(0.5)$ & $52(13.5)$ & $326(84.9)$ & $4(1.0)$ \\
\hline Doctor/nurse/ describe side effects of the drug & $3(0.8)$ & $217(56.5)$ & $157(40.9)$ & $7(1.8)$ \\
\hline Availability of prescribed drugs & $0(0)$ & $89(23.2)$ & 294(76.6) & $1(0.3)$ \\
\hline 13. Pain well controlled & $2(0.5)$ & $162(42.2)$ & $211(54.9)$ & $9(2.3)$ \\
\hline \multicolumn{5}{|l|}{ Physical environment items } \\
\hline 14. Clean service delivery rooms & $0(0)$ & 19(4.9) & $358(93.2)$ & $7(1.8)$ \\
\hline Quite atmosphere & $1(0.3)$ & $61(15.9)$ & $317(82.6)$ & $5(1.3)$ \\
\hline Drinking water has been availability & $0(0)$ & $252(65.6)$ & $129(33.6)$ & $3(0.8)$ \\
\hline 17. Clean toilets bathrooms & $0(0)$ & $239(62.2)$ & $141(36.7)$ & $4(1.0)$ \\
\hline $\begin{array}{l}\text { 18. Sign \& direction indicators were available to ease } \\
\text { ways }\end{array}$ & $11(2.9)$ & $272(70.8)$ & $96(25.0)$ & $5(1.3)$ \\
\hline \multicolumn{5}{|l|}{ Convenience items } \\
\hline $\begin{array}{l}\text { 19. Satisfied with overall waiting time to get whole } \\
\text { services }\end{array}$ & $0(0)$ & $76(19.8)$ & $308(80.2)$ & $0(0)$ \\
\hline 20. All services needed were available in the facility & $0(0)$ & $176(45.8)$ & $208(54.2)$ & $0(0)$ \\
\hline Cost for treatment were affordable & $2(0.5)$ & $195(50.8)$ & $185(48.2)$ & $2(0.5)$ \\
\hline
\end{tabular}

\subsection{Bivariable and Multi Variable Analysis}

Among the baseline variables fitted to binary regression model for bi-variable analysis: patient department, age, occupation, marital status, and educational level were significantly associated with patient satisfaction at alpha $5 \%$ $(\mathrm{p}<0.2)$.

Finally the covariates: patient department (age and occupation were found significant at alpha 5\% $(\mathrm{p}<0.05)$ with patient satisfaction (Table 3).

\section{Discussion}

This study showed that overall satisfaction of private wing patients with services obtained from the private wing at Bahirdar Felege Hiwot Referral Hospital was (57.8\%) with (95\% CI $(52.8 \%-63.1 \%)$, which is lower as contrasting with foreign studies done at public hospitals $(9,16,21)$. These variations may be due to the socio-cultural and economic status of the patients' in the particular areas of respective countries. Besides, the source of difference may also be methodological variation.

In contrasting with studies in Ethiopia: the overall satisfaction of this study is greater as compared with some public hospitals satisfaction studies $(12,13)$ The variations might be due to better services in the private wing as a result of patients' opportunity to choose their health personnel, particularly doctors; may also due to methodological variations. On the contrary it was lesser as compared with recent studies at public hospitals in Ethiopia $(1,2)$. The difference particularly in a study at JUTRH might be because of presence of many qualified health personnel, delivery of wide services, and availability of better instruments and equipments, since it is teaching referral hospital. There may be also higher expectations of patients on private wing services at Bahirdar Felege Hiwot Referral Hospital.

When we come to satisfaction scores of measuring items, high proportion of respondents in this study replied 'satisfied' for most factors (Table 2) as compared with studies $(1,6,9,11,16)$. The disparity may be due to real existence of satisfactory situations related to measuring factors in the private wing of BFHRH due to its specialty. On the other hand some crucial factors got lower satisfaction score to the scale 'satisfied' in this study. To mention some, presence of sign and direction indicators to ease the way in the hospital (25\%), availability of drinking water (33.6\%), describing side effects of drugs (40.9\%), and information regarding to symptoms look out after leaving the hospital (44\%). Therefore, maximize efforts towards them without compromising the other services is essential job to do so for betterment of private wing patient. 
In our study among base line variables, age, occupation, and patient department, are significantly associated with patients' satisfaction $(\mathrm{p}<0.05)$, Similarly age, and occupation were reported significantly associated with patient satisfaction in studies SHURH, as well as JUTRH, age is also significant with satisfaction in a study at Addis Ababa hospitals. However unlike our study educational status and frequency of visit are significantly associated in a study at JUTRH $(\mathrm{p}<0.05)(1,6,11,14)$. This distinction may be due to confounding effect, etc. Therefore doing researches with maximum sample size, and including variables as many as enough to control confounding effect, etc. is better to get true associations.

Pertaining to patient department, being outpatient reduce satisfaction by $59 \%$ as compared with inpatients (AOR 0.411 (95\% CI (0.243-0.696), which may be due to getting information about services, observe delivering services, know the reality and practicing it over the lengths of time.

Table 3. Bi-variable and multi-variable analysis showing factors affecting patient satisfaction, BFHRH, 2014 ( $n=384)$

\begin{tabular}{|c|c|c|c|c|}
\hline Variables & Satisfied $(n=222) n(\%)$ & Dissatisfied (n=162) n (\%) & $\operatorname{COR}(95 \% \mathrm{CI})$ & $\operatorname{AOR}(95 \% \mathrm{CI})$ \\
\hline \multicolumn{5}{|l|}{ Patient department } \\
\hline Inpatient & $77(67.5)$ & $37(32.5)$ & 1 & 1 \\
\hline Outpatient & $145(53.7)$ & $125(46.3)$ & $.557(.352-.882 *$ & $.411(.243-.696)^{* *}$ \\
\hline \multicolumn{5}{|l|}{ Age } \\
\hline $18-27$ & $80(73.4)$ & $29(26.6)$ & 1 & 1 \\
\hline $28-37$ & $80(65.0)$ & $43(35.0)$ & $.674(.384-1.185)$ & $1.158(.583-2.300)$ \\
\hline $38-47$ & $36(43.9)$ & $46(56.1)$ & $.284(.154-.522)^{* * *}$ & $.466(.221-.981)^{*}$ \\
\hline$>=48$ & $26(37.1)$ & $44(62.9)$ & $.214(.112-.408)^{* * *}$ & $.395(.178-.877)^{*}$ \\
\hline \multicolumn{5}{|l|}{ Occupation- } \\
\hline Farmer & $55(56.1)$ & $43(43.9)$ & 1 & 1 \\
\hline Merchant & $54(44.6)$ & $67(55.4)$ & $.630(.369-1.077)$ & $.514(.249-.1 .065)$ \\
\hline Government employee & $31(52.5)$ & $28(47.5)$ & $.866(.453-1.655)$ & $.728(.332-1.598)$ \\
\hline Private employee & $19(61.3)$ & $12(38.7)$ & $1.238(.542-2.826)$ & $.937(.345-2.543)$ \\
\hline Others@ & $63(84.0)$ & $12(16.0)$ & $4.105(1.968-8.560)$ & $2.907(1.085-.7 .790)^{*}$ \\
\hline \multicolumn{5}{|l|}{ Marital status- } \\
\hline Single & $72(69.2)$ & $32(30.8)$ & 1 & \\
\hline Married & $134(54.3)$ & $113(45.7)$ & $.527(.324-.857)^{*}$ & \\
\hline Divorced & $12(54.5)$ & $10(45.5)$ & $.533(.209-1.361)$ & \\
\hline Widowed & $4(36.4)$ & $7(63.6)$ & $.254(.069-.929)^{*}$ & \\
\hline
\end{tabular}

Being aged within 37- 47 years (AOR $0.466(95 \%$ CI $(0.221-0.981))$, and $48+$ years (AOR $0.395 \quad(95 \%$ CI (0.178-0.877)) have decreased satisfaction by $53 \%$ and $60 \%$ respectively as compared with ages within $18-27$ years. It may be due to an increment of expectations as well as the enhanced knowledge and experience as age gets higher.

Overall, to improve the satisfaction of patients, strengthening efforts to deliver integrated quality service is suggested. Particularly extending it to areas of sign and direction indicators to ease the way, drinking water, description of side effects of drugs, and information regarding to symptoms look out after leaving the hospital. Periodic patient satisfaction survey may also be institutionalized to provide feedback for continuous quality improvement.

This study had some limitations; first, the study used a descriptive cross-sectional design that cannot establish trends and causality between potential predictors and patient satisfaction. Second interview held on admitted patients might be inflated the result due to social desirability bias.

\section{Conclusion}

Overall private wing patient satisfaction $(57.8 \%)$ at $95 \%$ CI (52.8\%-63.1\%) computed from the different components of health care delivered at the private wing of the hospital is lower as compared with recent studies in public hospitals of Ethiopia.

High proportion of patients were dissatisfied with patient satisfaction measuring items, such as, availability of sign and direction indicators to ease the way in the hospital, availability of drinking water, description of side effects of drugs, and information regarding to symptoms look out after leaving the hospital.

Among the baseline characteristics patient department, age, and occupation were significantly associated with patient satisfaction $(\mathrm{p}<0.05)$.

This survey on private wing patient satisfaction may be the pioneer in our country in its kind which will be reinforce other researchers to do further studies in this area.

\section{Recommendations}

Policy makers need strengthen incessant and deep discussion with service users, givers and stake holders; as well as evaluate satisfaction periodically to provide feedback to the hospital to improve satisfaction through quality service.

Study Hospital require strengthen efforts to deliver integrated quality service to improve overall patient 
satisfaction at the private wing, and some hard work may needed to improve areas, like sign and direction indicators to ease the way, drinking water, description of side effects of drugs to patients, and delivery of information regarding to symptoms look out after leaving the hospital. Furthermore, Emphasis might be needed to outpatient care without compromising inpatient care.

Researchers may plan a comparative study triangulated with qualitative design with increased sample size.

\section{Acronyms}

$\begin{array}{ll}\text { AKTH } & \text { Aminu Kano Teaching Hospital } \\ \text { ANRS } & \text { Amhara National Regional State } \\ \text { ANRSHB } & \begin{array}{l}\text { Amhara Ntional Regional State Health } \\ \text { Beauro }\end{array} \\ \text { BFHRH } & \begin{array}{l}\text { Bahirdar Felege Hiwot Referal Hospital } \\ \text { BSC }\end{array} \\ \text { Bachelor of Science } \\ \text { CAHPS } & \begin{array}{l}\text { Consumer Assessment of Healthcare } \\ \text { Providers and Systems }\end{array} \\ \text { FMOH } & \text { Federal Ministry of Health } \\ \text { HMI } & \text { Hospital Management Initiative } \\ \text { HCS } & \text { Health Care System } \\ \text { HURH } & \text { Hawasa University Referral Hospital } \\ \text { IGMPH } & \text { Indira Gandhi Memorial Public Hospital } \\ \text { IPD } & \text { Inpatient department } \\ \text { IRRB } & \text { Institutional Review Board } \\ \text { JUTRH } & \text { Jimma University Teaching referral Hospital } \\ \text { MPH } & \text { Master of Public Health } \\ \text { OPD } & \text { Out Patients department } \\ \text { PH } & \text { Public Health } \\ \text { PHC } & \text { Primary Health Care } \\ \text { SPSS } & \text { Statistical Package for social Science } \\ \text { UOG } & \text { University of Gondar } \\ \text { WHO } & \text { World Health Organization } \\ & \end{array}$

\section{Authors' Contributions}

Yeshambel Agumas Ambelie pictured the original idea, designed the study and participated in all implementation stages of the project; analyzed the data and finalized to write the manuscript. Amsalu Feleke Demssie and Measho Gebreslassie Gebreegziabher were responsible for critically revising the proposal and the manuscript, also participated in its design and interpretation. All authors reviewed and approved the final manuscript.

\section{Competing Interests}

The authors declare that they have no competing interests

\section{Acknowledgment}

Our special thanks and sincere appreciation go to study participant, data collectors, the supervisor, and Bahirdar Felege Hiwot Referral Hospital.

\section{References}

[1] Assefa F. Mosse A. H/Michael Y. assessment of client satisfaction with healt service deliveries at Jimma University Teaching Hospital. Ethiopian Journal of Health Science. July $2011 ; 21$.

[2] Webster T. Mantopoulos J. Jackson E etal. A brief questionnaire for assessing patient healthcare experiences in low-income settings. International Journal for Quality in Health Care. 2011 April 30; 23:258-68.

[3] Redshaw M. BA PhD. Women as Consumers of Maternity Care: Measuring "Satisfaction" or "Dissatisfaction"? Blackwell Publishing Inc. 2008;35.

[4] Debono D. Travaglia J. complaints and patient satisfaction: a comprehensive review of the literature. 2009.

[5] Kwesiga D. Kiwanuka N. Kiwanuka S. a comparative analysis of client satisfaction among people recieving HIV/AIDS care from public and private health facilities In kabal destrict, Uganda 2010.

[6] Olijira L. Gebre-selassie S. Satisfaction with outpatient health services at Jimma Hospital, South West Ethiopia. The Ethiopian Journal of Health Development. 2001: .

[7] Donabedian. An Introduction to Quality Assurance in Health Care. Oxford University Press, USA 2002.

[8] Dr. F.M. Kimani. Guideline for the establishment and management of ameniety in public hospitals in Kenya. Febraury 2008.

[9] Iliyasu Z. Abubakar I. Lawan U etal. Patient satisfaction with services obtained from Aminu Kano Teaching Hospita, Kano,Northern Nigeria. Nigerian Journal of Clinical Practice December 2010;13:371-8.

[10] Abdosh B. The quality of hospital services in eastern Ethiopia: Patient's perspective. Ethiop Health Journal 2006;20:199-200.

[11] Chaka B. Davey G. adult patient satisfactiowith nursing care. 2004.

[12] Girmay A. assessment of client satisfactionwith patient services in Tigray zonal hospitals. 2006.

[13] Mitike G. Satisfaction on outpatient services in hospitals of the Amhara region, Ethiop. Medical Journal. 2002;40: 387 95.

[14] Tariku H. statistical analysis of ptients' satisfaction with hospital services: case study of Shashemene and Hawassa University Referral Hospitals, Ethiopia. May 2011.

[15] Ibrahim A. Patient satisfaction with the health service at the out patient department of indira gandhi memorial hospital, Male Maldive,India. 2008.

[16] Syed A. Shamila H. Jabeen R etal. Measuring patient satisfaction: a cross sectional study to improve quality of care at a tertiary care hospital. health line. January-June 2012; 3

[17] Sreenivas T. Suresh N. a study on patient satisfaction in hospitals. Internationa Journal of research management and bussiness. October 2012;1. 
[18] Bahirdar Felege Hiwot Referal hospital. guideline to private wing 2011.

[19] Federal Ministry of Health. Federal Ministry of Health Anual report. 2012.

[20] USAID Health system. Health Care Financing Reform in Ethiopia: Improving Quality and Equity. March 2012.
[21] Iloh G. Ofoedu J. Njoku p etal. Evaluation of patients' satisfaction with quality of care provided at the National Health Insurance Scheme clinic of a tertiary hospital in South- Eastern Nigeria. Nigeria Journal of clinical practice. 2012 15:469-74. 